\title{
Simultaneous effect of RCM key indicators, related to equipment lifecycle for maintenance strategies (in production systems)
}

\author{
Mohammad Zadhoosh ${ }^{1 *}$, Amir Afshin Fatahi ${ }^{2}$ \\ ${ }^{I}$ Department of Industrial Engineering, Faculty Engineering, Parand Branch, Islamic AzadUniversity, Parand, \\ Iran. M.Sc of Industrial Engineering \\ ${ }^{2}$ Department of Industrial Engineering, Faculty Engineering, Parand Branch, Islamic AzadUniversity, Parand, \\ Iran. Assistant Professor of Industrial Engineering \\ *Corresponding author E-mail: mzadhoosh@yahoo.com
}

Copyright $(2015$ Mohammad Zadhoosh, Amir Afshin Fatahi. This is an open access article distributed under the Creative Commons Attribution License, which permits unrestricted use, distribution, and reproduction in any medium, provided the original work is properly cited.

\begin{abstract}
In the modern industrial world, effective role of maintenance activities in the survival of organizations and enhancing their productivity is undeniable.

Variety of equipments in the industrial organizations and their exclusivities in terms of longevity and failures modes, clear the importance of choosing a strategy for the maintenance of any equipment. Thus, knowing the type of the failure is so important for maintenance manager and engineers.

Important introduced indicators in this domain such as indicator of reliability, MTBF and MTTR can be used to predicting and detecting approximate failure time and analyzing life cycle status.

On the other hand, due to fluctuating time of system availability because of work continuity and loss of a performance indicator, by combining RCM indicators and Overall Equipment Effectiveness (OEE) indicator the most compatible strategy could be chosen. The aim of this article which differs from other studies in this field is to apply a composed indicator, including different parameters of RCM, which is obtained based on the equipment life status.
\end{abstract}

Keywords: Maintenance; Reliability; Key Performance Indicators; Weibull Analysis; Life Cycle.

\section{Introduction}

Nowadays, reliability is a field which is widely used in various fields of engineering science. When we are contorted with equipment, we are curious to know how likely it will last longer than the time $\mathrm{t}$

Reliability Centered Maintenance (RCM) and Total Productive Maintenance (TPM) consider achievements by using different strategies and different analyzes. . Among all the parameters affecting these objectives, some parameters which affect all the objectives are MTTR and MTBF (\% R) and OEE indicators.

The results show that by using a certain statistical analysis, the life of the equipment, the degree of reliability or validity in any period, and finally, appropriate maintenance strategies specific to each phase of life can be achieved, and it can be concluded that the equipment in terms of reliability, the intervals between failures, the overall effectiveness of equipment and other functional parameters in each period has a different situation [1]. Therefore, the equipment at different stages of its life requires different maintenance policies. Studies on the use of RCM were started from 1965 in US aviation industry. John Moubray and his colleagues in the early 80s began to implement the RCM in the mining sector, manufacturing and production.

In 1990 with the added safety and environmental considerations by the Doctor Moubray, a new version of RCM, was released by the technical standards board of the United States called RCM II [2]. In traditional management, maintenance was considered as a non-important and non-productive tool, which had a slight advantage for organizations. However, in the modern approach of maintenance, the principle is keeping ready for the equipments and 
devices. The aim of the systematic and planned maintenance of equipment and machinery in this system would be zero emergency repairs and emergency stops, increase equipment reliability, enhance the ability to predict failure and periodic repairs and planned public facilities and maximize OEE [3]. This paper attempts to use KPI indicators simultaneously by recognizing equipment life during its operation period. An indicator which is called RCM and defined as a combinational formula included 4 main indicators of maintenance. By using this indicator the most appropriate strategy of practical maintenance could be provided for technical and maintenance managers. In other previous studies, such as strategies were considered only based on individual indicators and regardless of the equipment's life cycle. At the first, it is necessary to know the life cycle of equipment by using a certain statistical technique known as Weibull Analysis. In this case, deficiency in an industry field is the lack of attention to the life cycle of the equipment status and lack of understanding of techniques and statistical techniques in the analysis of the maintenance.

\section{The indicators used in the field of RCM}

\subsection{Reliability function}

In short, we say, if $\mathrm{F}(\mathrm{t})$ is the density distribution function, and then according to the formula (1) reliability function is defined as:

$$
\mathrm{R}(\mathrm{t})=\overline{\mathrm{F}}(\mathrm{t})=\mathrm{P}(\mathrm{T} \geq \mathrm{t})
$$

\subsection{Failure rate function}

Also, if $\mathrm{f}(\mathrm{t})$ is the density function then failure rate function known as hazard rate would be:

$$
h(\mathrm{t})=\frac{\mathrm{f}(\mathrm{t})}{\mathrm{R}(\mathrm{t})}
$$

\subsection{Mean time between failures (MTBF)}

MTBF is one of the most common phrases in maintenance to describe reliability for repairable equipments.

This scale usually measures MTBF of equipment during its normal life cycle. In time between failures MTBF is expressed in terms of time and usually does not involve failure rate early life (first life) and wear out of the equipment. For equipments that are not serviceable and need to be replaced, the MTTF indicators are used. Numerical values of MTBF and MTTF are very close together and the differences between their numerical values depend on the value of MTTR. MTBF indicator is considered as a tool for measuring preventive maintenance system [4]. Another application of this indicator is to predict and detect the approximate time of occurrence of the next failure and subsequently necessary planning to deal with the next failure and needed repayments. Analytically this indicator is calculated according to these formulas:

$$
\begin{aligned}
& \text { MTBF }=\frac{\sum(\text { Down Time-Up Time })}{\text { Number of Failure }}=\frac{\mathrm{T}}{\mathrm{N}} \\
& \mathrm{MTBF}=\mathrm{MTTF}+\text { MTTR }
\end{aligned}
$$

\subsection{Mean time to repair (MTTR)}

This Iindicator is the most common term which is used to describe reliability in repairable systems.

The required time for repairing failures, includes troubleshooting, resolution downtime, repairs, and any tests that we need to ensure the elimination of the problem. Simply, when the equipment is not useable, up until to reuse it, If equipment that in $\mathrm{n}$ past time has broken down and the time required to repair the system at times $\mathrm{i}$ equal to ti, then, the required time for repairing, according to the formula (5) is:

$\mathrm{TR}=\frac{\sum_{i=0}^{n} t_{i}}{n}$

\subsection{Availability of equipment (per availability)}

By definition, it is obvious that reliability means the continuity of perfect function without disability, In other words, the probability of system remaining or a part in good functional condition without any failure. Clearly this definition for reliability is an inappropriate scale for systems with continuous operation, and it is prone to failure because in most of 
these systems malfunctions, inherent in the system and it are acceptable. In this case, another definition for availability cloud be presented; it is the probability of finding the system in necessary condition for performing in the future. Because failure is always a probability, although the system will stop responding and crash, but finding the probability that it is available for use will be considered. Availability as a numeric value is probable and is between zero and one. Unlike reliability, time to repair is considered in the availability and calculated according to formula (6):

Availability $(\% \mathrm{~A})=\frac{\mathrm{MTBF}}{\mathrm{MTBF}+\mathrm{MTTR}}$

Previous formula shows that greater MTBFs can close the availability to 100 percent. If MTTR is small, then its influence is relatively low but whenever MTTR gained great amounts this amount was decreased significantly. In other words, we can say that in a reparable system with high MTBF and low MTTR, availability will be close to 1.

\subsection{Overall equipment effectiveness (OEE)}

OEE can be used within both RCM and TPM fields. By using this indicator the time that the equipment is in well-being status can be calculated. This indicator is almost one of the new indicators in the area of maintenance. OEE is used to recognize the effectives of the failures and calculating the general safety of the equipments. Since this index is the product of three main indicators in the field of production, including: reliability ratio, technical or mechanical, availability and quality so it is very strong and very telling indicator guidance for comparing the performance of production systems. OEE formula is the product of these three parameters.

Availability(\%) $\times$ Performance (\%) $\times$ Quality(\%)

In TPM standard the ideal level for effectiveness indicator is about $85 \%$ which is obtained from ideal level of top three factors (TPM,Naka jima). It means:

$(\mathrm{A} \% \times \mathrm{P} \% \times \mathrm{Q} \%)=\% 90 \times 95 \times \% 99=\% 85$

\section{Lifecycle}

In Failure Mode and Effects Analysis techniques (FMEA), six failure models are considered. Each one is based on the analysis of failure rates over time. The first and the most traditional pattern of failure and the failure rate, known as the Bathtub Curve. In this model, in the beginning the failure rate decreases, then it would be constant, and then it has an increasing trend. These three cases represent three stages of the life cycle. The first stage is sealing or Infant Mortality, at the second stage in which the failure ratio is constant is called useful life, and the third stage which failure ratio is increased due to aging equipment is known as wear out [5].

In Figure 1, the failure rate function with respect to time, which represents 3 life cycle stage of industrial equipment, is shown.

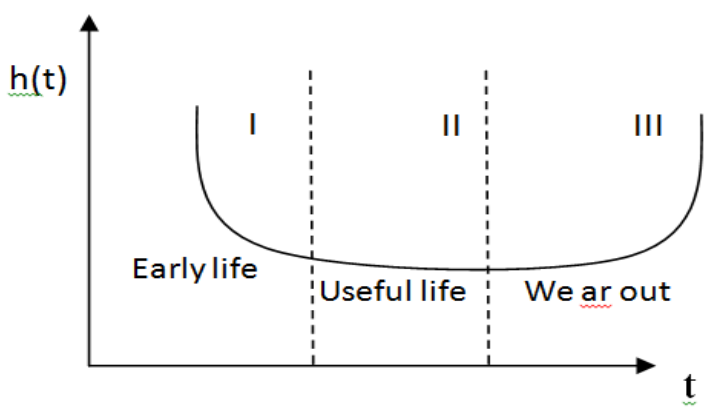

Fig. 1: Bathtub Curve Associated with the Life Cycle of Equipment

\section{Weibull analysis method}

Usually four types of statistical continuous distributions, including: normal distribution, exponential distribution, hyperexponential distribution and Weibull distribution are used in order to calculate the reliability and status of equipment during its life. Failures in early life or sealing periods are respectively fitted by hyper exponential and for a useful life period fitted by exponential and wear out period are respectively fitted by normal or Weibull distribution. Equipments with decreasing, constant and increasing failure rates in different parts of their lifecycle usually follow weibull distribution. So their data are fitted by this distribution. Weibull is the most practical distribution in reliability 
discussions. The main function of this important distribution is to analyze the reliability of equipments in modeling of components erosion [6].

By definition, non-negative random variable $\mathrm{T}$ has a Weibull distribution with parameters $\alpha$ and $\beta$, if its distribution functions are like equation:

$$
\mathrm{F}(\mathrm{t})=1-\mathrm{e}^{-(\mathrm{t} / \alpha)^{\beta}} \mathrm{t}>0 \quad \alpha, \beta>0
$$

Also its reliability and failure rate functions are according to equations 10 and 11:

$$
\begin{aligned}
& R(t)=e^{-(t / \alpha)^{\beta}} \\
& (\mathrm{t})=\frac{\beta}{\alpha^{\beta}} \cdot t^{\beta-1} \quad t>0
\end{aligned}
$$

This distribution has two main parameters; shape and scale that are shown by $\beta$ and $\alpha$.while normal and exponential distribution have not shaped parameter and always have a concrete form. By changing in $\alpha$ and $\beta$ amount, this distribution can be changed into another distribution. The shape parameter of this distribution is effective on density functions, reliability functions and failure rate function that is why this distribution is known so flexible, and it is widely used in reliability modeling. In Weibull analysis, it has been demonstrated that for different values of $\beta$ each stage of the life cycle of the equipment could be identified.

\subsection{Weibull analysis}

After fitting the failure data in equipment and obtaining TTF times, if obtained distribution is consistent with Weibull Analysis, then we go to its shape parameter and according to it determine the equipment status in its lifecycle.

1) If $0<\beta<1$, the Weibull distribution has a decreasing failure rate and data are related to sealing or early life period.

2) If $\beta=1$, failure rate is constant, then it represents a special case of the exponential distribution and represents the useful life of the equipment.

3) If $\beta>1$, the failure rates are increasing, indicating the wear out of the equipment to warn.

This distribution has a third parameter known as location parameter which shows the distribution shift, and in most researchers is ignored, i.e. $\gamma=0$ is considered.

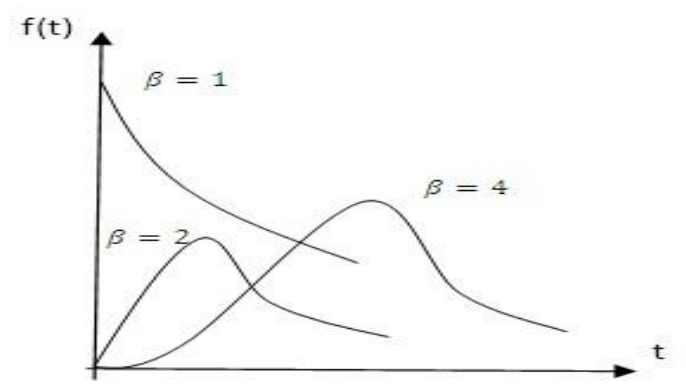

Fig. 2: Different Status of Weibull Distribution for Different B

Figure 2 shows different Weibull distributions with different $\beta$ and $\gamma=0, \alpha=1$ parameters.
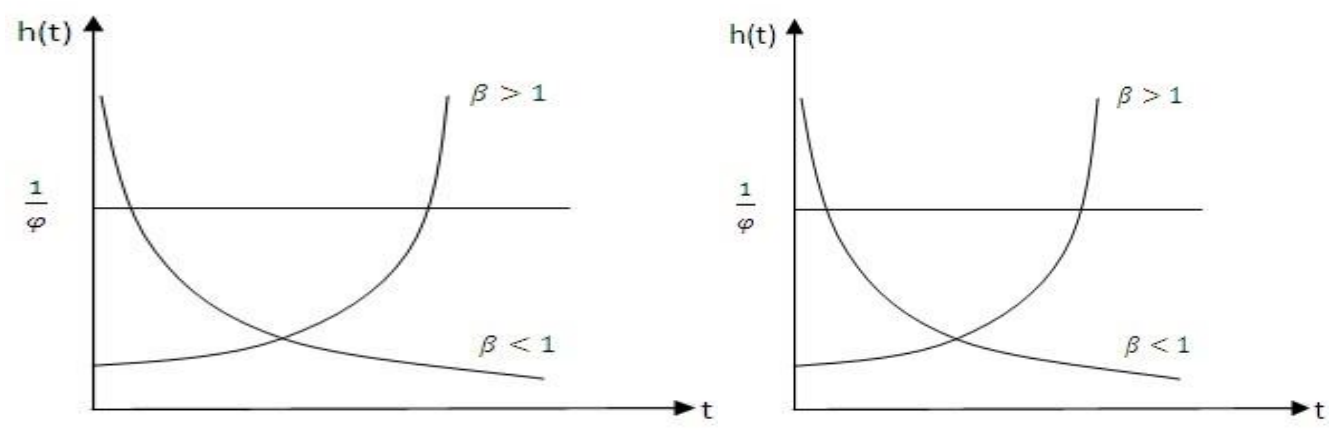

Fig. 3: Different Status of Weibull Failure Rate with Different B 


\section{Specifying an effective indicator related to RCM parameters.}

After determining the basic parameters of RCM as MTTR, MTBF and reliability of equipment as well as important indicator of OEE by understanding the situation, then a proper strategy could be adopted for each period. According to type of industry and equipment location, if we have weight of each indicator above shown with wi, then we can use the following formula known as RCM coefficient.

$\mathrm{C}_{\mathrm{RCM}}=\frac{\sum_{i=0}^{n}\left[w_{i} \times \mathrm{KPI}_{i}\right]}{\sum_{i=0}^{n} w i}$

(Here KPI are our basic indicators)

It should be noted that in any production system with goal setting for MTTR and MTBF indicators, these parameters can be converted to percent.

\section{Relation between coefficient of RCM and lifecycle}

To determine the relation between the life cycle and coefficient OF RCM ,it could be stated that just detecting the status of equipment lifecycle on the chart that is characterized by Weibull analysis in this study, is not an effective and appropriate method, in order for obtaining an appropriate maintenance strategy. But we need a method by which every part of the lifecycle status be analyzed on the chart. For example, during the useful life of the equipment that major policies run; however, the failure rate is fixed in a specific time period the beginning and end of this process, namely, entering the sealing stage up to the ablation threshold period, are different. This difference is not determined by diagram of life cycle because our information is characterized by the space parameter $(\beta=1)$ so here an indicator is needed that determines and analyses the entrance and exit of this stage. In this research, this work is done by the coefficient of RCM. At this stage even whenever failure rate was approximately fixed but reliability, MTBF and OEE indicators were changing. Analysis of these parameters could be obtained by combined ratio in relation (12).In in this paper, the influence of these factors over the life cycle diagram, is used simultaneously and is studied as a case study.

\section{Determining the maintenance strategy associated with each life cycle of rotary kilns in cement industry.}

In the proposed method, which has been done in the RCM area in Sepahan Cement Company, obtained data are analyzed by total stoppages and special FMEA forms related to equip 3300 tone rotary kiln clinker. After getting over the initial sealing and during two separated eight-month period, following accurate study and analysis of how each failure event, planned and emergency stoppage are separated. These two periods are analyzed simultaneously using Minitab and Easyfit software. After The Weibull analysis for failure in two separate 8-month period, the useful life cycle and the wear out of the kiln is determined. After calculating equation (12) and RCM coefficients for each period for each kiln, then with an overview it could be analyzed.

During The entire life of the rotary kiln, RCM coefficient range after the initial period (sealing) starts from $85 \%$ and reaches to t $30 \%$ at the end of its useful life. According to obtained $\beta$ from Weibull analysis, maintenance decisions would be made.

\subsection{First period}

As noted above, the first period of equipment's life is after initial startup or after a major overhaul, called sealing period. In this case, the failure rate of large equipment such as clinker kiln is initially high but bypassing the time this rate would be decreased and reaches to normal point which the main reasons for this are: sealing system and its compatibility with operating conditions, manufacturing defects and poor quality control. Thus, the failure density function at this stage follows the hyper exponential distribution or Weibull with $0<\beta<1$. In cement industry, this stage means initial start-up after overhaul not operates smoothly at the beginning of the production and successive stops. In the field of Maintenance Engineering, recognizing this period is very important. So there is no need for decision making on equipment maintenance. Hence the equipment should be allowed to pass this period and reaches to be initial sealing stage.

\subsection{Second period}

During the useful life of equipment and where RCM coefficient reaches about $85 \%$ of the numerical values, the equipment is in perfect safety and level of reliability follows constant failure rate or $[\mathrm{h}(\mathrm{t})=\mathrm{const}$. And most failures and 
stops of kiln caused by accident or random failures, which may be due to environmental conditions, random loading or human errors. This period can be divided into two parts.

Where RCM coefficient is $55 \%$ to $88 \%$, and then it shows us $55 \%$ to $33 \%$. In term of statistical, fitted distribution in these ranges are exponential distribution or Weibull with parameters $\beta=1$ is. In cement industry, this stage is after starting-up (sealing) and smooth functioning of the system, and most of the EM stops are accidental or emergency. At The first part of this period, it means the range of $85 \%$ to $55 \%$, maintenance system should be effective and active. And mostly includes, preventive maintenance, corrective maintenance, improving maintenance and time based maintenance, where the affairs of industrial cleaning, lubrication and executive $5 \mathrm{~s}$ and technical inspection are so important. At the second stage, namely reaching from 55\% to 30\% downfall stage is reminded in another word; we are entering the wear out level. So some actions such as short repairs, applying strong maintenance programs, knowing condition and performance of equipment by applying CBM and condition monitoring, non-destructive tests, Ultrasonic and vibration analyses are required.

\subsection{Third period}

By passing the useful lifecycle and entering wear out period of the kiln where coefficient of RCM reaches to less than $30 \%$ or in Weibull analysis $1<\beta$, failure rate of furnace would be strongly increased and acute conditions is be applied to the system. From a statistical standpoint during this period normal and Weibull distributions would be well fitted to failure times. In this period survival analysis, proves that the number of reliability is less than useful lifecycle. OEE reaches to less than $50 \%$ and interval between failures is very short and kiln repairing would not be effective. In cement industry, this period causes production fall and completely stops the production line so other departments are also required to be stopped. I such a situation the expert engenders should be prepared to do an overhaul of the system. Furthermore, applying any maintenance policy except Breakdown Maintenance or overhaul is forbidden. After overhaul a correct applying preventive maintenance and well TBM we expect kiln returns to the beginning of the second period. In other words, to its optimum performance and high reliability.

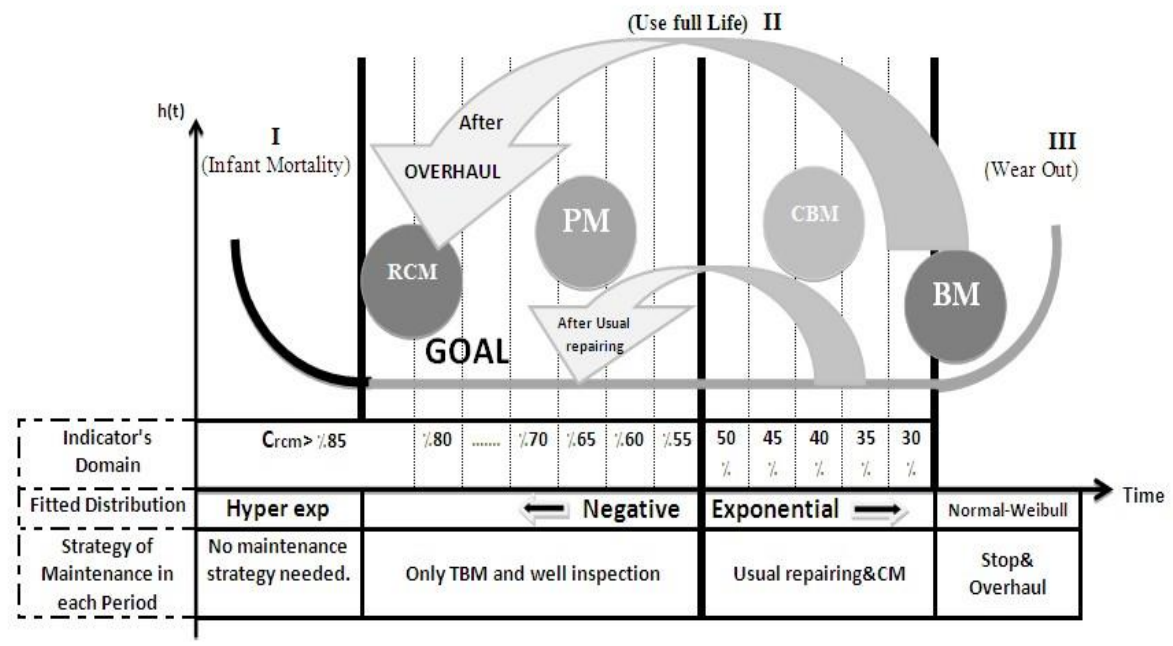

Fig. 4: Life Cycle's Analysis and Maintenace's Strategy of Each Period

Table 1: Executive Maintenace for Each Period and Related Economic Justification

\begin{tabular}{|c|c|c|c|}
\hline Economic Justification & Strategy & $\begin{array}{l}\text { Reliability } \\
\text { (Range) }\end{array}$ & $\begin{array}{l}\text { Life } \\
\text { Cycle's } \\
\text { Periods }\end{array}$ \\
\hline $\begin{array}{l}\text { Execution of each maintenance type, cause overhead } \\
\text { costs }\end{array}$ & $\begin{array}{l}\text { No Maintenance Strategy is } \\
\text { needed }\end{array}$ & Random & Early Life \\
\hline time & $\begin{array}{l}\text { Only Lubricaion \& cleaning \& } \\
\text { inspection (PM-TBM-PDM- } \\
\text { NDT) }\end{array}$ & $\begin{array}{l}\% 55 \leq \mathrm{R} \\
<\% 85\end{array}$ & $\begin{array}{l}\text { Useful Life } \\
\text { (1) }\end{array}$ \\
\hline Reduce EM costs & $\begin{array}{l}\text { Usual repairing Corrective } \\
\text { Maintenance \& } \mathrm{CBM}(\mathrm{Cm})\end{array}$ & $\begin{array}{l}\% 30 \leq \mathrm{R} \\
<\% 55\end{array}$ & $\begin{array}{l}\text { Useful Life } \\
\text { (2) }\end{array}$ \\
\hline $\begin{array}{l}\text { Return to useful life }(1)(\% 55 \leq \mathrm{R}<\% 85) \& \text { Reduce } \\
\text { costs of PM than EM }\end{array}$ & Overhaul & $\mathrm{R}<\% 30$ & Wear out \\
\hline
\end{tabular}




\section{Abbreviations}

1) RCM:Reliability Centered Maintenance

2) TPM:Total Productive Maintenance

3) MTTF:Mean Time To Failure

4) MTTR:Mean Time To Repair

5) RF:Reliability Factor

6) OEE:Overall Equipment Effectiveness

7) KPI:Key Performance Indicators

8) FMEA:Failure Mode And Effects Analysis

9) Bath Tub Curve

10) Coefficient of RCM

11) Random Loading

12) CM:Corrective Maintenance

13) TBM:Time Based Maintenance

14) CBM:Condition Based Maintenance

15) NDT:Non Destructive Test

16) BM:Breakdown Maintenance

17) PM:Preventive Maintenance

\section{References}

[1] Karbasian, M. Reliability Engineering, Iran, Tehran. Naghous Publish. (2011).

[2] Moubray,John. Reliability centered maintenance, second Edition. (1990).

[3] Haj shirmohamadi, A. Maintenance Planning, Iran, University of Isfahan, (2010).

[4] Kumar, D., Knezevic, J. Maintenance free operating period an alternative measure to MTBF and failure rate for specifying reliability. Reliability Engineering and System Safety, 64 (1999) pp: 127-131. http://dx.doi.org/10.1016/S0951-8320(98)00048-9.

[5] Valdebenito, MA. Beaurepaire, P. Reliability based optimization of maintenance scheduling of mechanical components under fatigue. Comput. Methods Appl. Mech. Engrg. 221-222 (2012) pp: 24-40.

[6] Bernethy,R. The new Weibull Handbook, Reliability \& Statistical Analysis, British Library, London, Fourth Edition (2001). 